\title{
La interpretación de las cláusulas del contrato estatal en el marco del orden jurídico ${ }^{1}$ \\ Interpretation of the terms of the state contract according to the legal system
}

\author{
NOHORA ELENA PARDO POSADA ${ }^{2}$ \\ nohora09@gmail.com \\ CARLOS ARTURo HERNÁNDEZ ${ }^{3}$ \\ carloshernandez@gmail.com
}

RESUMEN

La interpretación del contrato estatal, propende por dilucidar la voluntad de los contratantes, con el fin de dar un correcto y razonado alcance a las obligaciones que de él se generan, dentro del marco del respeto a la normatividad 124 que gobierna la actividad del Estado, como son la aplicación de los postulados que rigen la función administrativa, y de los principios de transparencia, economía, responsabilidad y buena fe.

PALABRAS CLAVES: contrata estatal, autonomía de la voluntad, interpretación

Fecha de recepción: marzo 6 de 2013

Fecha de aceptación: abril 10 de 2013

\section{ABSTRACT}

State contract interpretation, tends to elucidate the will of the parties, in order to give a correct and rational scope to the obligations which are generated within the framework of respect for the regulations governing the activity of the State, as are the application of the principles governing the administrative function and the principles of transparency, economy, accountability and good faith.

KEYWORDS: State contract, autonomy, interpretation

1. Artículo de reflexión basado en uno de los resultados del proyecto de investigación, patrocinado por la Universidad La Gran Colombia, Facultad Derecho, titulado: Análisis crítico de la Contratación Estatal en Colombia.

2. Docente Investigadora de la Universidad la Gran Colombia, Abogada de la Universidad Libre. Magister en Derechos Administrativo y Especialista en Derecho Administrativo de la misma Universidad, especialista en docencia Universitaria Universidad La Gran Colombia. Maestrando de la Universidad del Rosario Argentina en derecho procesal. Docente de la Universidad La Gran Colombia - Bogotá.

3. Abogado, magister en Filosofía del Derecho y Teoría Jurídica, Candidato a Doctor en Derecho Universidad Externado de Colombia, Docente Investigador Externo de la facultad de Derecho, de la Universidad La Gran Colombia y Universidad Autonoma de Colombia. 


\section{Introducción}

A partir de la vigencia de la Ley 80 de 1993, el ordenamiento jurídico adoptó la categoría del contrato estatal definido por el artículo 32 como aquel acto jurídico creador de obligaciones a cuya celebración concurra una de las entidades estatales que menciona el artículo 2 ibídem.

Para referirse al contrato administrativo se adopta en las disposiciones legales un criterio subjetivo $\mathrm{u}$ orgánico, teniendo en cuenta la naturaleza de los sujetos u órganos que intervienen en la formación del vínculo contractual, para efectos de determinar que los contratos podrán catalogarse como estatales únicamente en cuanto en uno de sus extremos, al menos, se encuentre una entidad estatal.

Ahora bien, a propósito de la expresión contratos estatales (artículos 8-2, 11, 13, 27, 28, 32, 39, 40,
70, entre otros), que la Ley 80 asimila y equipara con los contratos del Estado (artículos 41 y 44, entre otros) y contratos de las entidades estatales (artículos 1, 6, 8-1, 13, 32-1, 32-2, 32-3, 32-4, 39, 66, dio lugar al surgimiento de la clasificación que lleva su nombre, cabe señalar la utilización de normas que en modo alguno los circunscriben a los específicos contratos de que se ocupa el estatuto de contratación estatal ${ }^{4}$ en razón al criterio subjetivo u orgánico, que por disposición legal se inaplica a las entidades exentas del régimen contractual por virtud de la ley 1150 de $2007^{5}$.

En esta materia, el Consejo de Estado en sentencia de fecha agosto 20 de 1998 precisó, que el contrato estatal ${ }^{6}$ esta regido por el principio de la autonomía de la voluntad, a su vez por la protección del interés público y la vigilancia de los recursos, contratos que pueden asumir dos categorías: los contratos estatales ${ }^{7}$ y $\operatorname{los}$

4. En ese sentido amplio cabe entender la expresión "contrato estatal" que utiliza el artículo 32 de la Ley 80/93, al igual que la expresión "contrato del estado" que aparece artículo 141 del código de procedimiento administrativo y de lo contencioso administrativo.

5. Colombia. Congreso de la República. Ley 1150 de 2007, artículo 15 que modificó el artículo 32. (...) «Parágrafo $1^{\circ}$. Los Contratos que celebren los Establecimientos de Crédito, las compañías de seguros y las demás entidades financieras de carácter estatal, no estarán sujetos a las disposiciones del Estatuto General de Contratación de la Administración Pública y se regirán por las disposiciones legales y reglamentarias aplicables a dichas actividades."

Ibídem, artículo 16. "De las Entidades exceptuadas en el sector Defensa. Los contratos que celebren Satena, Indumil, El Hotel Tequendama, la Corporación de Ciencia y Tecnología para el desarrollo de la industria naval, marítima y fluvial -Cotecmar- y la Corporación de la Industria Aeronáutica Colombiana -CIAC-, no estarán sujetos a las disposiciones del Estatuto General de Contratación de la Administración Pública y se regirán por las disposiciones legales y reglamentarias aplicables a su actividad".

6. Consejo de Estado. Sala de lo Contencioso Administrativo. Sección Tercera. Sentencia de agosto 20 de 1998. Magistrado Ponente, Dr. Juan de Dios Montes Hernández. “... Coherente desde el punto de vista de semántica jurídica con el órgano público contratante, se acuñó la categoría "contratos estatales", los cuales, de conformidad con el art. 32 de la ley 80 de 1993, son todos los actos jurídicos generadores de obligaciones que celebren las entidades estatales que el mismo ordenamiento enumera".

7. Ibídem. "Contratos estatales, propiamente dichos, que son aquellos que celebran las entidades públicas a que se refiere la ley 80 de 1993, y que por ende se regulan integramente por el régimen establecido en esta ley. Por regla general, adquieren este carácter en razón del ente público contratante, es decir, se definen desde el punto de vista orgánico. Las controversias que se deriven de este tipo de contratos y de los procesos de ejecución o cumplimiento serán de conocimiento de la jurisdicción contenciosa administrativa."

Criterio Jurídico Garantista. Año 5, No. 8. Ene.-Jun. de 2013. ISSN: 2145-3381. Fundación Universidad Autónoma de Colombia, Bogotá. 
contratos especiales ${ }^{8}$ sujetos a un régimen legal propio.

Afirmó, el Consejo de Estado, que el contrato como manifestación de la autonomía de la voluntad de los celebrantes con objeto de crear obligaciones, es un acto jurídico. Esa expresión de voluntad puede ser explícita o implícita, ya se deduzca claramente del mismo acuerdo o se colija por interpretación de su clausulado, respectivamente ${ }^{9}$, a su turno, la clasificación de un contrato en estatal no conlleva per se, la aplicación de normas de derecho público, debe tenerse en cuenta el objeto contractual que da lugar a la aplicación de normas de derecho privado conservando su fin de prestación de servicios público, por tanto se aplica un régimen jurídico mixto, integrado por normas de derecho público 126 y de derecho privado ${ }^{10}$., fijado el término contrato estatal, cabe preguntarse ${ }_{\mathrm{C}}$ En caso de controversia contractual por el alcance de las cláusulas, como deben interpretarse?, interrogante que será objeto del presente artículo, para ello se acudirá a la fuentes primarias como la Constitución, la ley y la jurisprudencia en el tema, utilizando para ello el método analítico y descriptivo.

\section{La metodología}

En el presente texto se hará un análisis comparativo de micro nivel para extraer patrones en el conjunto de sentencias de la del Consejo de Estado que da cuenta de dichas realidades complejas y se realiza un análisis de macro nivel con casos nacionales. Los dos tipos principales de método comparativo difieren respecto al método orientado a las variables que se enfocan en explicaciones generalizadas, mientras el método orientado a los casos da énfasis a la realidad compleja.

\section{La interpretación del contrato estatal}

La interpretación del querer de las partes enmarcado en el principio de autonomía de la voluntad que se materializa en las cláusulas del contrato estatal, presenta como límite los fines del Estado ${ }^{11}$, a su turno, el artículo 28 de la ley 80 de 1993, obliga a escoger la interpretación de las cláusulas del contrato que tenga en cuenta los fines y principios de la ley, la buena fe y el equilibrio de las prestaciones recíprocas.

8. Ibídem, "Contratos especiales sujetos a un régimen legal propio. Por regla general, el juez a quien compete conocer de sus controversias es el juez administrativo, en razón de que su celebración y ejecución constituye una actividad reglada, es decir, es el ejercicio pleno de una función administrativa.

9. Consejo de Estado. Sala de Consulta y servicio civil. Magistrada ponente María Elena Giraldo Gómez. siete (7) de febrero de 1997.

10. Consejo de Estado. Sala Plena de lo Contencioso Administrativo. Sentencia de septiembre 23 de 1997. Expediente S-701-Contractual. Actor: Diego Giraldo Londoño. Magistrado Ponente: Dr. Carlos Betancur Jaramillo.

11. Ley 80 de 1993, artículo 40.- "Del contenido del contrato estatal. Las estipulaciones de los contratos serán las que de acuerdo con las normas civiles, comerciales y las previstas en esta ley, correspondan a su esencia y naturaleza. Las entidades podrán celebrar los contratos y acuerdos que permitan la autonomía de la voluntad y requieran el cumplimiento de los fines estatales.

En los contratos que celebren las entidades estatales podrán incluirse las modalidades, condiciones y, en general, las cláusulas o estipulaciones que las partes consideren necesarias y convenientes, siempre que no sean contrarias a la Constitución, la ley, el orden público y a los principios y finalidades de esta ley y a los de la buena administración.(...) 
No obstante, la interpretación puede establecerse en el contrato como cláusula excepcional a favor de la administración y excepcionalmente a favor de los contratistas, como sucede, verbigracia con la posibilidad del contratista para terminar unilateralmente el contrato por modificaciones en más del 20\% del valor del contrato. Este tipo de cláusulas son preceptuadas y desarrolladas, en gran parte, por los artículos 14, a 19 de la Ley 80 de 1993, y responden a las finalidades de la contratación estatal, orientadas a la protección de los intereses generales y la prestación de los servicios públicos: En este estado, es necesario recordar los contratos sujetos a este tipo de cláusulas que se enlistan a continuación: a) todos los contratos estatales que tengan por objeto el ejercicio de una actividad que constituya monopolio estatal; b) los contratos estatales cuyo objeto lo constituya la prestación servicios públicos; c) los contratos para la explotación y concesión de bienes del Estado y; d) los contratos de obra pública ${ }^{12}$.

Señalado la posibilidad de interpretar un contrato en razón al poder excepcional cabe analizar este evento cuando surge por la interpretación de las cláusulas contractuales, que se funda en la teoría general, al respecto considera que para entender o interpretar un contrato es necesario desarrollar tres pasos: interpretación, calificación e integración ${ }^{13}$. La interpretación consiste en establecer la común intención de las partes objetivada en el texto o en las declaraciones o comportamientos lícitos, congruentes y relevantes, por el uso, de

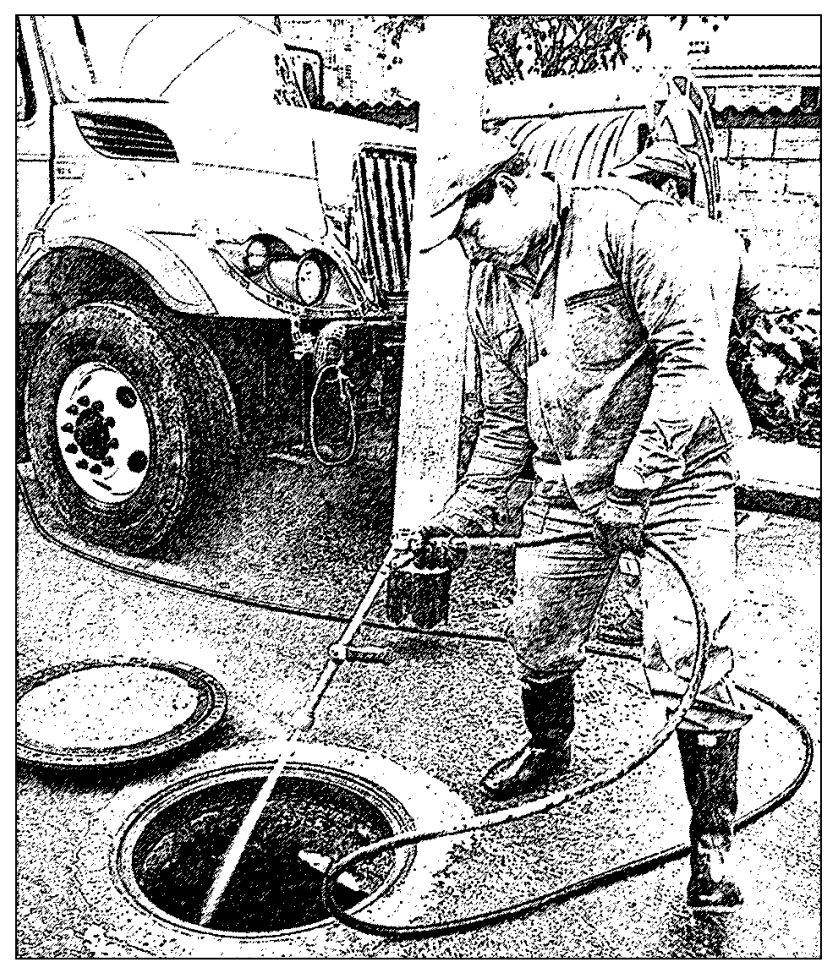

La interpretación puede establecerse en el contrato como cláusula excepcional a favor de la administración

y excepcionalmente a favor de los contratistas, como sucede, verbigracia con la posibilidad del contratista para terminar unilateralmente el contrato por modificaciones en más del $20 \%$ del valor del contrato. Este tipo de cláusulas son preceptuadas y desarrolladas, en gran parte, por los artículos 14, a 19 de la Ley 80 de 1993.

12. Consejo de Estado. sala de lo contencioso administrativo, sección tercera - subsección a, Consejero ponente: Mauricio Fajardo Gómez, mayo nueve (09) de dos mil doce (2012).

13. Consejo de Estado. Sala de lo contencioso administrativo, sección tercera, subsección b, consejero ponente: Danilo Rojas Betancourt, Veintinueve (29) de agosto de dos mil doce (2012) 
criterios subjetivos y objetivos establecidos en el Código Civil ${ }^{14}$. Por su parte, la calificación hace referencia a la tipificación o el encuadramiento del acuerdo alcanzado por las partes dentro de las categorías legales comprendidas en el estatuto de contratación, en las leyes que lo reforman, en el Código Civil, en el Código de Comercio o en las leyes especiales que resulten aplicables al caso concreto.

La integración corresponde al fenómeno en virtud del cual, una vez determinado el tipo contractual, las partes o el juez encuentran que al lado de las determinaciones convencionales que tienen fundamento en la autonomía de las partes, se agregan, adicionan o suman otras obligaciones y otros derechos que tienen título en las normas imperativas y supletorias, en los usos y costumbres, en la buena fe y en la equidad ${ }^{15}$. De lo que se colige que frente a la interpretación de un contrato es imperativo el cumplimiento de la secuencia lógica de interpretación, calificación e integración por parte e cualquiera de los extremos de la relación contractual y del operador judicial si es del caso., eventos que serán objeto de análisis posteriormente.

Por su parte, el principio de la autonomía contractual, establecido en el artículo 1602 del Código Civil colombiano ${ }^{16}$, impone que al efectuarse la interpretación de las cláusulas del contrato deberá acudirse a la común intención de las partes exteriorizada, la cual corresponderá, por encima del sentido estrictamente gramatical de la expresión, a la voluntad común y originaria que acompañó a los contratantes, en concordancia

14. "Artículo 1618.- Conocida claramente la intención de los contratantes, debe estarse a ella más que a lo literal de las palabras". "Artículo 1619.- Por generales que sean los términos de un contrato, sólo se aplicarán a la materia sobre que se ha contratado". "Artículo 1620.- El sentido en que una cláusula puede producir algún efecto, deberá preferirse a aquel en que no sea capaz de producir efecto alguno". "Artículo 1621.- En aquellos casos en que no apareciere voluntad contraria, deberá estarse a la interpretación que mejor cuadre con la naturaleza del contrato. Las cláusulas de uso común se presumen aunque no se expresen”. "Artículo 1622.- Las cláusulas de un contrato se interpretarán unas por otras, dándosele a cada una el sentido que mejor convenga al contrato en su totalidad. Podrán también interpretarse por las de otro contrato entre las mismas partes y sobre la misma materia. O por la aplicación práctica que hayan hecho de ellas ambas partes, o una de las partes con aprobación de la otra parte”. "Artículo 1623.- Cuando en un contrato se ha expresado un caso para explicar la obligación, no se entenderá por solo eso haberse querido restringir la convención a ese caso, excluyendo los otros a que naturalmente se extienda". "Artículo 1426.- No pudiendo aplicarse ninguna de las reglas precedentes de interpretación, se interpretarán las cláusulas ambiguas a favor del deudor. Pero las cláusulas ambiguas que hayan sido extendidas o dictadas por una de las partes, sea acreedora o deudora, se interpretarán contra ella, siempre que la ambigüedad provenga de la falta de una explicación que haya debido darse por ella”.

15. Consejo de Estado, Sala de lo Contencioso Administrativo, Sección Tercera, Subsección B, sentencia del 28 de septiembre de 2011 , expediente n. ${ }^{\circ} 18837$, C.P. Danilo Rojas Betancourth: "En general, con el término "integración” se hace referencia a formas de intervención sobre el contrato que van más allá del amplio desarrollo de la lógica de la declaración de los contratantes y que se agregan a su actividad en la construcción definitiva de sus obligaciones y derechos. En otros términos, el fenómeno de la integración debe ser entendido como el medio de intervención de la voluntad pública en las relaciones contractuales, lo cual significa que al lado de las determinaciones convencionales que tienen fundamento en el acuerdo de las partes, es necesario considerar las prescripciones que tienen título en la ley o en las otras fuentes externas a su acuerdo".

16. “Todo contrato legalmente celebrado es una ley para los contratantes, y no puede ser invalidado sino por su consentimiento mutuo o por causas legales” 
con el artículo $1618^{17}$ del Código Civil y con la jurisprudencia de la sección tercera del Consejo de Estado ${ }^{18}$.

Ahora bien, en el orden jurídico colombiano por
expresa disposición del código civil es posible acercarse a la interpretación real de las cláusulas contractuales, sin embargo los antecedentes de la norma se remontan a Roma ${ }^{19}$, en especial en la racionalización jurídica de Domat $^{20} \mathrm{y}$, posteriormente en Pothier ${ }^{21}$, que se reprodujo en los códigos civiles Europeos ${ }^{22}$ y de América

17. "Conocida claramente la intención de los contratantes, debe estarse a ella más a que lo literal de las palabras"

18. Consejo de Estado, Sala de lo Contencioso Administrativo, Sección Tercera, sentencia de 15 de febrero de 1991, referencia 5973, C.P. Carlos Betancur Jaramillo: "El poder de interpretación que tienen las partes de un contrato no se discute, ni en el derecho privado ni en el público. El mismo código civil en sus artículos 1618 y siguientes trae una serie de normas orientadoras a ese respecto. Y es obvio que así sea porque en la ejecución y cumplimiento de los contratos pueden surgir discrepancias o dudas sobre el alcance de ciertas cláusulas ofrases que entorpezcan su desarrollo. Discrepancias o dudas que deben ser despejadas en primer término por las mismas partes y que en última instancia será el juez el que las despeje cuando aquéllas no hayan logrado un acuerdo y como consecuencia se haya producido el rompimiento de la relación negocial. Pero ese poder interpretativo que en el derecho privado es equivalente y no coercitivo, como que una de las partes no le podrá imponer a la otra una determinada interpretación, en el derecho público presenta unas características diferentes"; sentencia de 4 de junio de 1993 , referencia 7215, C. P. Daniel Suárez: "Del texto anterior y dentro de una sana hermenéutica y para esto habrá que seguirse los artículos 1618 y ss del C.C., lo primero que se deduce del contenido de la cláusula transcrita es la intención de las partes...”; sentencia de 11 de mayo de 1999, referencia 10196, C. P. Ricardo Hoyos Duque: "La Sala considera que a pesar de las incongruencias que presentó el contrato, este aspecto no solo debe analizarse a la luz de la mencionada disposición, sino también de otros preceptos contemplados en el Código Civil 1618 para la interpretación de los contratos. El propósito de esta norma no es otro que lograr que entre los contratantes prevalezca la voluntad real sobre la voluntad declarada."

19. El principio de interpretación referido se incorpora, entre otros pasajes del Digesto (traducción de I. GARCIA DEL CORRAL. Cuerpo del derecho civil romano, Barcelona, 1897): "D.50,16,2 19 Papiniano, Respuestas, libro II.- Se determinó que en las convenciones se atienda a la voluntad de los contratantes más bien que a las palabras. Así pues, cuando los municipios hubieren dado en arrendamiento un fundo tributario con la condición de que le perteneciera al heredero del que lo tomó, pudo ser transferido también al legatario del derecho de los herederos"

20. M. Domat, Les loix civiles dans leur ordre naturel; le droit public, et legum delectus (tome premier), Paris 1771, p. 26: "Regla 1. Las oscuridades y dudas deben interpretarse por la intención común de los contratantes. Las convenciones deben ser formadas por el consentimiento mutuo de las partes, y cada una debe explicar sincera y claramente lo que promete y lo que pretende. Y es por su intención común que se explica aquello que puede aparecer en la convención como oscuro o dudoso". "Regla 4 "La intención se prefiere sobre la expresión. Si los términos de una convención parecen contrarios a las intenciones de los contratantes, y estas intenciones resultaren evidentes, se debe atender a la intención por encima de los términos".

21. R.J. Pothier, Oeuvres de R-J Pothier. Les Traites du Droit Francais, (tome premier), Bruxelles, 1829 "Primera regla. 91. Se debe, en las convenciones, investigar cuál ha sido la intención común de las partes contratantes más que el sentido gramatical de los términos."

22. Código Civil francés, artículo 1156: "Se debe, en las convenciones, investigar cuál ha sido la intención común de las partes contratantes más que detenerse en el sentido literal de los términos"; Código Civil alemán, artículo 133: "En la interpretación de una declaración de voluntad ha de investigarse la voluntad real y no atender al sentido de la expresión”; Código Civil italiano, artículo 1362: "Intenciones de los contratantes.- En la interpretación del contrato se debe indagar cuál ha sido la común intención de las partes y no limitarse al sentido de las palabras. Para determinar la común intención de las partes se debe valorar su comportamiento completo, también posterior a la celebración del contrato"; Código Civil español, artículo 1281.- "Si los términos de

Criterio Jurídico Garantista. AÑo 5, No. 8. Ene.-Jun. de 2013. ISSN: 2145-3381. Fundación Universidad Autónoma de Colombia, Bogotá. 
Latina $^{23}$ durante los siglos XIX y XX. Normas que tiene en común el privilegiar la intención demostrable de los contratantes; hecho que impone al juez, como interprete contractual la búsqueda de la intención contractual atendiendo no sólo a las claúsulas contractuales sino a los actos administrativos precontractuales en especial el pliego de condiciones $^{24}$, a la oferta presentada por el oferente, a las peticiones y actos contractuales; la autonomía e intención contractual se mate- rializa en el contrato, pero tiene en cuenta los actos administrativos anteriores, concomitantes y posteriores a ella si son del caso.

Toda vez que el Estatuto de Contratación de la Administración Pública, no contiene reglas especiales en materia de interpretación del contrato estatal, resulta necesario acudir a los criterios de interpretación previstos en el Código Civil Colombiano $^{25}$,incorporados al Estatuto General

un contrato son claros y no dejan duda sobre la intención de los contratantes se estará al sentido literal de sus cláusulas. Si las palabras parecieren contrarias a la intención evidente de los contratantes, prevalecerá ésta sobre aquellas”.

23. Código Civil del Distrito Federal de México, artículo 1851: "Si los términos de un contrato son claros y no dejan duda sobre la intención de los contratantes se estará al sentido literal de sus cláusulas. Si las palabras parecieren contrarias a la intención evidente de los contratantes, prevalecerá ésta sobre aquellas”; Código Civil de Brasil, artículo 112: "En las declaraciones de voluntad se atenderá más la intención que al sentido literal del lenguaje”.

24. Consejo de Estado, Sala de lo Contencioso Administrativo, Sección Tercera, Sentencia de octubre 31 de 2007, Expediente 15475, C.P. Mauricio Fajardo Gómez.

"El pliego de condiciones tiene una doble e importante finalidad: de una parte constituye el fundamento de la oferta presentada por el contratista, quien debe acogerse estrictamente a sus reglas para proponer los costos del proyecto, los plazos de su ejecución, pero también, como resulta obvio, para calcular su utilidad o remuneración que, en últimas constituye el móvil que lo lleva a contratar y, de otra, en él se encuentran inmersas las condiciones de la futura contratación, toda vez que muchas de sus precisiones y previsiones se convierten en verdaderas cláusulas contractuales, las cuales permiten determinar los aspectos que llevaron a las partes a formalizar el acuerdo de voluntades y, sobre todo, han de ser útiles al momento de establecer el alcance de sus obligaciones o prestaciones, incluyendo los aspectos de índole técnico, económico y financiero".

25. Código Civil Colombiano. ARTÍCULO 1618. Prevalencia de la intención. Conocida claramente la intención de los contratantes, debe estarse a ella más que a lo literal de las palabras.

ARTÍCULO 1619. Limitaciones del contrato a su materia. Por generales que sean los términos de un contrato, solo se aplicarán a la materia sobre que se ha contratado.

ARTÍCULO 1620. Preferencia del sentido que produce efectos. El sentido en que una cláusula puede producir algún efecto, deberá preferirse a aquel en que no sea capaz de producir efecto alguno.

ARTÍCULO 1621. Interpretación por la naturaleza del contrato. En aquellos casos en que no apareciere voluntad contraria, deberá estarse a la interpretación que mejor cuadre con la naturaleza del contrato.

Las cláusulas de uso común se presumen aunque no se expresen.

ARTÍCULO 1622. Interpretaciones sistemáticas, por comparación y aplicación práctica. Las cláusulas de un contrato se interpretarán unas por otras, dándosele a cada una el sentido que mejor convenga al contrato en su totalidad.

Podrán también interpretarse por las de otro contrato entre las mismas partes y sobre la misma materia.

O por la aplicación práctica que hayan hecho de ellas ambas partes, o una de las partes con aprobación de la otra parte. 
de Contratación en virtud de lo normado por el artículo $13^{26}$ de la Ley 80 de 1993, también por remisión del Código de Comercio ${ }^{27}$, en el evento de que el contrato se celebre con un comerciante, a la luz de lo dispuesto por el artículo $28^{28}$ de la misma Ley 80 respecto de los criterios de interpretación de los contratos estatales.

\section{Las reglas de interpretación de los con- tratos $^{29}$}

La jurisprudencia contenciosa administrativa ha estudiado las reglas de interpretación de contratos estatales y ha afirmado al respecto:

Se distingue entre interpretación y valoración del contrato la primera ocurre para establecer el negocio jurídico y sus efectos, no es particular para cada una de las partes sino en su conjunto; $y$ la segunda para las repercusiones jurídicas de las cláusulas contractuales acordadas por las partes.

La interpretación del negocio jurídico, cuando de contratos se trata, no pretende establecer el querer dispositivo de cada uno de los contratantes individualmente considerado, lo que conllevaría a modificaciones posteriores sino que propende por establecer la intención común de las partes contratantes. Para lograrlo se parte de la común intención de las partes mediante la aplicación de una serie de reglas principales, también llamadas subjetivas por la doctrina, que se extraen en la intención de los contratantes, al tener literal plasmado en las cláusulas contractuales (art. 1618 del C. C.), que las estipulaciones de un contrato

ARTÍCULO 1623. Interpretación de la inclusión de casos dentro del contrato. Cuando en un contrato se ha expresado un caso para explicar la obligación, no se entenderá por solo eso haberse querido restringir la convención a ese caso, excluyendo los otros a que naturalmente se extienda.

ARTÍCULO 1624. Interpretación a favor del deudor. No pudiendo aplicarse ninguna de las reglas precedentes de interpretación, se interpretarán las cláusulas ambiguas a favor del deudor.

Pero las cláusulas ambiguas que hayan sido extendidas o dictadas por una de las partes, sea acreedora o deudora, se interpretarán contra ella, siempre que la ambigüedad provenga de la falta de una explicación que haya debido darse por ella.

26. Artículo 13 "Los contratos que celebren las entidades a que se refiere el artículo 2o. del presente estatuto se regirán por las disposiciones comerciales y civiles pertinentes, salvo en las materias particularmente reguladas en esta ley.

27. Código de Comercio

Artículo 822._Los principios que gobiernan la formación de los actos y contratos y las obligaciones de derecho civil, sus efectos, interpretación, modo de extinguirse, anularse o rescindirse, serán aplicables a las obligaciones y negocios jurídicos mercantiles, a menos que la ley establezca otra cosa.

28. ARTÍCULO 28. DE LA INTERPRETACIÓN DE LAS REGLAS CONTRACTUALES. En la interpretación de las normas sobre contratos estatales, relativas a procedimientos de selección y escogencia de contratistas y en la de las cláusulas y estipulaciones de los contratos, se tendrá en consideración los fines y los principios de que trata esta ley, los mandatos de la buena fe y la igualdad y equilibrio entre prestaciones $y$ derechos que caracteriza a los contratos conmutativos."

29. M. Bianca. Derecho civil. El contrato. Universidad Externado de Colombia, Bogotá 2007, p. 429 y siguientes; L. Cariota Ferrara. El negocio jurídico. Aguilar, Madrid 1956, p. 607 y siguientes; W. Flume. El negocio jurídico. Fundación Cultural del Notariado, 
pueden interpretarse por la de otro que las partes hayan celebrado sobre la misma materia (art. 1622 inc. $2^{\circ}$ ) o por la aplicación práctica que de ellas hayan hecho (art. 1622 inc. $3^{\circ}$ ), que las cláusulas deben interpretarse unas por otras dándole a cada una el sentido que más convenga al contrato en su totalidad (art. 1622 inc. $1^{\circ}$ ), que si en un contrato se expresa un caso para explicar la obligación se entiende que esa mención no es restrictiva sino ejemplificativa (art. 1623), y que se entiende que la expresiones generales contenidas en el negocio sólo se aplican a la materia sobre la que se ha contratado (art. 1619).

En términos actuales y de una manera general es posible afirmar, que las cláusulas oscuras deben interpretarse en contra de quien las redactó o pre132 dispuso porque siendo de su cuenta la confección de la cláusula se impone con más vigor en él la carga de la claridad pues así lo exige la buena fé contractual, en especial si se tiene en cuenta el deber de información y el deber que tiene todo contratante de velar no sólo por su propio interés sino también por el interés del otro ya que el contrato cumple finalmente con una función económica y social. Por lo tanto, las cláusulas ambiguas se interpretan a favor del deudor (art. 1624 inc. $1^{\circ}$ ), y que las cláusulas oscuras que hayan sido extendidas o dictadas por una parte se interpretarán contra ella si la ambigüedad proviene de una explicación que ésta ha debido dar (art. 1624 inc. $\left.2^{\circ}\right)$.

La regla de interpretación atrás citada se remonta al derecho romano clásico, tomando el siguiente pasaje "Celso expresaba que 'cuando en una estipulación se duda cual sea el objeto de lo hecho, la ambigüedad va contra el que estipula' ${ }^{30}$, opinión ésta que reiteraba Ulpiano al señalar que 'cuando en las estipulaciones se duda que es lo que se haya hecho, las palabras han de ser interpretadas contra el estipulante' ${ }^{31}$.

Obra también, como antecedente de la interpretación de las reglas oscuras en contra de quien la redacto el concepto a cargo de los jurisconsultos romanos que señalaron que estipulante presentaba el tex to de la stipulatio y el promissor adhería a lo predispuesto, en consecuencia quien redactó la estipulación era libre para emplear con latitud las palabras'. ${ }^{32}$

"Pues bien, en términos actuales y de una manera más general podríamos afirmar que las cláusulas oscuras deben interpretarse en contra de quien las redactó o predispuso porque siendo de su cuenta la confección de la cláusula se impone con más vigor en él la carga de la claridad pues así lo exige la buena fe contractual, en especial si se tiene en cuenta el deber de información y el deber

Madrid 1998, p. 351 y siguientes; F. De Castro y Bravo. El Negocio jurídico. Editorial Civitas, Madid 1997, p. 73 y siguientes; E. Betti. Teoría general del negocio jurídico. Editorial Revista de Derecho Privado, Madrid 1959, p. 237 y siguientes.

30. Consejo de Estado. Sección Tercera. Magistrado ponente Jaime Orlando Santofimio Gamboa Expediente 18.762, Acción Contractual. Bogotá D.C julio siete de dos mil once.

31. Ibídem, p.21

32. Ibídem, p. 21. 


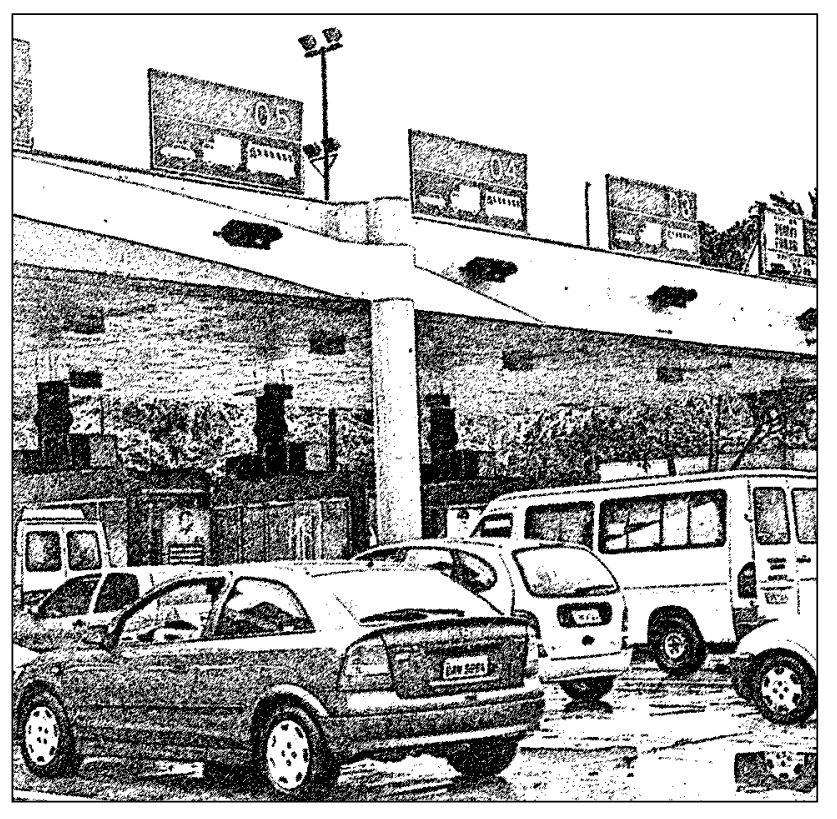

que tiene todo contratante de velar no sólo por su propio interés sino también por el interés del otro ya que el contrato cumple finalmente con una función económica y social.

"Ya se comprenderá entonces que estos deberes se aquilatan cuando se trata de la satisfacción del interés general mediante la prestación de los servicios públicos y se utilizan para ello los esquemas contractuales.

"Pero por supuesto, se reitera, esta regla de interpretación que se viene comentando es de carácter subsidiario pues sólo puede acudirse a ella si no es posible dilucidar en primer lugar con las otras reglas la común intención de los contratantes."33
La finalidad de la contratación estatal, está orientada a la protección de los intereses generales y la prestación de los servicios públicos: los contratos sujetos a este tipo de cláusulas se enlistan a continuación: a) todos los contratos estatales que tengan por objeto el ejercicio de una actividad que constituya monopolio estatal; b) los contratos estatales cuyo objeto lo constituya la prestación servicios públicos; c) los contratos para la explotación y concesión de bienes del Estado y; d) los contratos de obra pública.

\section{Debido proceso un paso necesario para la interpretación}

El debido proceso en materia contractual ha pasado por una serie de etapas que inician con su negación, teniendo en cuenta que en la constitución de 1886 no se establecía como tal y es en el tránsito constitucional en el amparo del decreto O 1 de 1984 que extiende el debido proceso a las actuaciones administrativas, hoy previsto en el artículo 3 y 35 del CPACA.

Ante un panorama de protección al ciudadano en cumplimiento del texto constitucional se destaca la introducción positiva, en el art. 17 de la ley 1150 de $2007^{34}$, que consagra como principio

33. Consejo de Estado, Sala de lo Contencioso Administrativo, Sección Tercera, Subsección C, Sentencia de julio 7 de 2011 , Expediente 18.762 , C.P. Jaime Orlando Santofimio Gamboa.

34. El debido proceso será un principio rector en materia sancionatoria de las actuaciones contractuales.

En desarrollo de lo anterior y del deber de control y vigilancia sobre los contratos que corresponde a las entidades sometidas al Estatuto General de Contratación de la Administración Pública, tendrán la facultad de imponer las multas que hayan sido pac- 
rector de la contratación estatal al debido proceso, el propósito de la norma es afirmar lo que constitucionalmente es indiscutible, es respeto en las actuaciones administrativos y el control de las mismas.

El debido proceso como principio rector en materia contractual se aplica en primera instancia a las actuaciones sancionatoria, si bien, el mandato es expreso no es excluyente de las demás actuaciones contractuales, por cuanto sería contrario al mandato constitucional del artículo 29 vulnerar el debido proceso en otras instancias procesales por ejemplo en la interpretación contractual ${ }^{35}$.

Si la interpretación surge a iniciativa de la entidad y en atribución a las facultades exorbitantes el 134 debido proceso se circunscribe al respecto de los derechos del contratista y a la clase de contrato perfeccionado $^{36}$, a su turno si es ejercida por las partes se impone el cumplimiento de los fines del Estado, de los principios de transparencia, economía, publicidad, celeridad y del debido proceso entre otros, todos en procura de establecer la intención de la cláusula oscura de conformidad con la intención de las partes que deberá ceñirse a su vez a lo establecido en la constitución y la ley.

\section{Conclusiones}

Con la interpretación del contrato se persigue constatar el convenio negocial, la determinación de sus efectos y la integración de estos, sin comprender en ella la calificación del acto pues esto es propio de una actividad diferente como es la valoración jurídica del acto celebrado.

Sin embargo no debe perderse de vista que si las partes han señalado los efectos del contrato, la verificación de este señalamiento corresponde a una labor interpretativa mientras que lo atinente a las repercusiones jurídicas de lo fijado por los contratantes hará parte de la valoración.

Para terminar, la interpretación del contrato estatal, propende por dilucidar la voluntad de los contratantes, con el fin de dar un correcto y razonado alcance a las obligaciones que de él se generan, dentro del marco del respeto a la normatividad que gobierna la actividad del Estado, como son la aplicación de los postulados que rigen la función administrativa, y de los principios de transparencia, economía, responsabilidad y buena fe.

tadas con el objeto de conminar al contratista a cumplir con sus obligaciones. Esta decisión deberá estar precedida de audiencia del afectado que deberá tener un procedimiento mínimo que garantice el derecho al debido proceso del contratista y procede sólo mientras se halle pendiente la ejecución de las obligaciones a cargo del contratista. Así mismo podrán declarar el incumplimiento con el propósito de hacer efectiva la cláusula penal pecuniaria incluida en el contrato

35. Consejo de Estado, sentencia de 30 de noviembre de 2006, exp. 30.832

36. Consejo de Estado, Sección tercera, magistrado ponente Enrique Gil Botero, Radicación número: 25000-23-26-000-1994-00225O1(16367), julio 23 de 2010. 


\section{Bibliografía}

Estatuto general de la contratación de la administración pública. Sistema de eruditos prácticos. Legis, Bogotá, 2011.

I. Garcia Del CORRAl. Cuerpo del derecho civil romano, Barcelona, 1897

M. DOMAT, Les loix civiles dans leur ordre naturel; le droit public, et legum delectus (tome premier), Paris 1771 , p. 26.

R.J. PothiER, Oeuvres de RJ. PothiER. Les Traites du Droit Francais, (tome premier), Bruxelles, 1829, Primera regla. 91.

Código Civil francés, artículo 1156.

Código Civil italiano, artículo 1362.

Código Civil español, artículo 1281.

Código Civil del Distrito Federal de México, artículo 1851.

Código Civil de Brasil, artículo 112.

Consejo de Estado, Sala de lo Contencioso Administrativo, Sección Tercera, Sentencia de octubre 31 de 2007, Expediente 15475, C.P. Mauricio Fajardo Gómez.

Consejo de Estado. Sala de lo Contencioso Administrativo. Sección Tercera. Sentencia de agosto 20 de 1998. Radicación n. ${ }^{\circ} 14202$. Actor: Universidad del Tolima. Magistrado Ponente, Dr. Juan de Dios Montes Hernández.

Consejo de Estado. Sala Plena de lo Contencioso Administrativo. Sentencia de septiembre 23 de 1997. Expediente S-701-Contractual. Actor: Diego Giraldo Londoño. Magistrado Ponente: Dr. Carlos Betancur Jaramillo.

Consejo de Estado, Sala de lo Contencioso Administrativo, Sección Tercera, referencia 5973, C.P. Carlos Betancur Jaramillo, sentencia de 15 de febrero de 1991.
Consejo de Estado. Sala de Consulta y servicio civil. Magistrada ponente María Elena Giraldo Gómez. siete (7) de febrero de 1997.

Consejo de Estado. Sala Plena de lo Contencioso Administrativo.. Expediente S-701-Contractual. Magistrado Ponente: Dr. Carlos Betancur Jaramillo. Sentencia de septiembre 23 de 1997

Consejo de Estado. Sala de lo Contencioso Administrativo. Sección Tercera. Magistrado Ponente, Dr. Juan de Dios Montes Hernández. Sentencia de agosto 20 de 1998

Consejo de Estado, Sala de lo Contencioso Administrativo, Sección Tercera, Sentencia de octubre 31 de 2007, Expediente 15475, C.P. Mauricio Fajardo Gómez

Consejo de Estado. Sección Tercera. Magistrado ponente Jaime Orlando Santofimio Gamboa Expediente 18.762, Acción Contractual. Bogotá D.C julio siete de dos mil once (2011).

Consejo de Estado, Sala de lo Contencioso Administrativo, Sección Tercera, Subsección B, expediente n. ${ }^{\circ} 18837$, C.P. Danilo Rojas Betancourth. Sentencia del 28 de septiembre de 2011.

Consejo de Estado, Sala de lo Contencioso Administrativo, Sección Tercera, Subsección C, Expediente 18.762, C.P. Jaime Orlando Santofimio Gamboa. Sentencia de julio 7 de 2011. Consejo de Estado. sala de lo contencioso administrativo, sección tercera - subsección a, Consejero ponente: Mauricio Fajardo Gómez, mayo nueve (09) de dos mil doce (2012).

Consejo de Estado. Sala de lo contencioso administrativo, sección tercera, subsección b, consejero ponente: Danilo Rojas Betancourt, Veintinueve (29) de agosto de dos mil doce (2012).

M. Bianca. Derecho civil. El contrato. Universidad Externado de Colombia, Bogotá 2007, p. 429. 